\title{
The business of accreditation
}

\author{
David E. Winchester, MD, MS, ${ }^{a}$ Ray E. Moseley, PhD, ${ }^{b}$ and Robert Hendel, MD $^{c}$ \\ a Division of Cardiovascular Medicine, Department of Medicine, University of Florida College of \\ Medicine, Gainesville, FL \\ ${ }^{\mathrm{b}}$ University of Florida College of Medicine, Gainesville, FL \\ ${ }^{c}$ University of Miami Miller School of Medicine, Miami, FL
}

doi: $10.1007 / \mathrm{s} 12350-014-0021-3$

\section{See related article, pp. 496-503}

The accreditation and certification of health care facilities and individual providers by nongovernmental organizations are integral to contemporary medical practice. Some accreditation processes are functionally mandated because they are closely tied to reimbursement or securing practice privileges. Examples of this would include the American Board of Internal Medicine (ABIM) and its subspecialties for physicians and The Joint Commission for hospitals. ${ }^{1,2}$ Other accreditations are more voluntary and convey to others an expertise in a specialized area. Examples here would include the American Board of Clinical Lipidology for physicians and the American Nurses Credentialing Center Magnet Recognition Program for health care facilities., ${ }^{3,4}$

Accreditation and certification are widely used methods for demonstrating, through independent external review, a voluntary commitment by facilities and individuals to achieve accepted or exceptional standards as part of the health care system. Accreditations and certifications systems have expanded during the past several decades. ${ }^{5}$ Broadly, the goals of accreditations and certifications are to improve the quality of health care that we provide by various methods, such as creating and testing standard knowledge sets for individual providers, monitoring ongoing maintenance of knowledge and skills, developing and evaluating performance

Reprint requests: David E. Winchester, MD, MS, Division of Cardiovascular Medicine, Department of Medicine, University of Florida College of Medicine, 1600 SW Archer Road, PO Box 100277, Gainesville, FL 32610-0277; david.winchester@medicine.ufl.edu J Nucl Cardiol 2015;22:504-6.

$1071-3581 / \$ 34.00$

Copyright (c) 2014 American Society of Nuclear Cardiology. care metrics, and assuring facility processes and infrastructure for patient safety and quality. Many accreditations and certifications are a mutually beneficial relationship, bringing a sense of pride and accomplishment to the certified and expanding the reach of the certifier.

The hope, of course, is that accreditations and certifications translate into better outcomes for our patients. For physician certification, some evidence of a modest benefit on outcomes have been described. ${ }^{6-8}$ Links between achievement of accepted metrics of quality care and improvement of patient outcomes have been difficult to demonstrate. ${ }^{9}$ When the Joint Commission adopted door-to-balloon time under 90 minutes as a quality metric in their accreditation process, times on the metric fell dramatically. The most recent analysis from the National Cardiovascular Data Registry, however, suggests that reducing this time has not translated into an improvement in in-hospital mortality. ${ }^{10}$

Accreditations and certifications are not without costs. In the year ending of December 2013, the Joint Commission reported revenue of $\$ 199,520,144$, largely from accreditation and surveying fees. ${ }^{11}$ The consolidated revenues of the American Board of Medical Specialties and its subsidiaries were $\$ 16,547,000$ as of December 2012. ${ }^{12}$ These financial reports also do not account for the substantial indirect costs to facilities and individuals in terms of labor, physical plant redesign, renovations, board review courses, and productivity opportunity costs required to achieve the accreditations and certifications.

The expansion of some accreditation and certification services may be reaching a point of diminishing returns. The ABIM recently made significant changes to its maintenance of certification program and met with significant concerns from physicians and professional societies as the direct and indirect costs were dramatically increased with no appreciable change in the value to the certified physician or demonstrable improvement 
in outcomes for their patients. ${ }^{13}$ The ABIM has agreed to review the changes to their physician certification process, albeit reluctantly. For organizations whose primary responsibility is evaluative, it may seem a natural progression to continually expand in scope. This phenomenon is not inherently good or bad but may be more pronounced when constraints, like market competition, are absent.

Like many accrediting and certifying organizations, the ABIM is alone in their field and has to contend with minimal or no competition. This is not the case with certification of nuclear cardiology laboratories. Certification is mandated to seek reimbursement from the Centers for Medicare and Medicaid Services (CMS) under the Medicare Physician Fee Schedule for the technical component of advanced diagnostic imaging, including nuclear imaging and positron emission tomography. Because CMS accepts accreditation from multiple bodies, laboratory directors have options for which organization they choose to be accredited by. ${ }^{14}$ The Government Accountability Office published a report in 2013 on the effect of this mandate which included a summary of the accreditation market. At the time, the Intersocietal Accreditation Commission (IAC) led the field with $72 \%$ of the market share for nuclear medicine facilities. ${ }^{15}$

The past several years have seen increasing scrutiny of the medical community for its relationships with a variety of industries. Presently, the United States government is implementing a system for disclosure of all transfers of value from industry to physicians into a database that will be freely accessible to the public. ${ }^{16}$ Disclosures of relationships are now commonplace in educational settings, such as formal presentations and at national meetings. Some professional societies, such as the American College of Cardiology (ACC), have developed their own robust disclosure systems. The ACC system is mandatory, even for nonmembers, before participating in any college activities, such as submission of abstracts for the national meeting.

The ACC also has developed Principles for Relationships with Industry, which describe policies on governance of the organization as well as expectations for how individuals will conduct themselves. The Principles define a relationship with industry as "all relationships with for-profit and other entities involved in the production, marketing, distribution, or selling of health care goods, services, consultation or information consumed by patients, investors and/or physicians. This may include relationships with government entities as well as not-for-profit entities, such as academic institutions." ${ }^{17}$ Relationships that the ACC considers relevant include consulting fees, honoraria, serving on speaker's bureaus, serving as an officer or director, ownership or partnership, research grants, salary, and other financial benefits. As 'entities providing health care services consumed by patients, investors and/or physicians', organizations that provide accreditation and certification services would qualify as industries for the purposes of disclosure and people affiliated with them would have relevant relationships to disclose.

In this issue of the Journal of Nuclear Cardiology ${ }^{\circledR}$, Jerome et al report the results of a survey conducted on medical and technical directors of nuclear cardiology laboratories accredited by the IAC. ${ }^{18}$ The survey had a low response rate $(11.6 \%)$ typical of a voluntary, emailbased survey with few responses provided by physicians $(10.4 \%)$. The vast majority of respondents (95\%) felt that accreditation was important. The authors conclude that "the accreditation process is demanding", and that "facilities find the process to be valuable", The results are predictable considering that the survey respondents are affiliated with labs already electing to be accredited.

As a not-for-profit entity involved in the production of health care services, consultation, or information consumed by patients, investors and/or physicians, the IAC would seem to qualify as "industry", including by the ACC definitions. Three authors on the manuscript provide their primary affiliation as with the IAC, which would seem to be an appropriate industry relationship to disclose to the readers. Additionally, it would be helpful for the readers to understand whether this research was conducted under the oversight of an independent review board or another objective body.

The aforementioned observations do not detract from the work of the IAC or from accreditation and certification in general. For over 20 years, the IAC has been working towards one mission, "Improving health care through accreditation." 19 In that time, the IAC has merged product lines making it easier to pursue multiple certifications and shifted its processes online to improve access. The IAC is itself invested in certification, having obtained International Organization for Standardization 9001:2008 and 27001:2005 standards. Other accrediting and certifying bodies have done their part to improve with time. Many will recall the struggle of having to travel across the country to watch a fixed loop of image clips on monitors several feet away in order to achieve certification in echocardiography. Now that process can be completed in any of a number of testing centers, likely within your own city. To the extent possible, accreditation and certification processes have been driven by science, even going so far as to withdraw quality metrics if proven ineffective. ${ }^{20}$

The business of accreditation and certification is a sizeable and growing industry which provides valuable services to the medical community as independent external arbiters of high quality care. The management 
of physician relationships with the accreditation industry, as with all health care industries, is integral to contemporary medical practice and research. As adjudicators of quality, it is critical that accrediting bodies have unquestionable integrity, including their use of consultants and writing groups. We support the publication of data which demonstrate the real and perceived values of accreditation and certification processes, such as the manuscript by Jerome et al, as these data promote the continued efforts to improve the quality of imaging and medical practice. Relationships with accreditation and certification industry partners should be carefully addressed so as not to detract from the value of this work.

\section{Disclosures}

Dr Winchester would like to disclose having voluntarily achieved certification in several specialties from the American Board of Internal Medicine and others. He has accepted funding from industry to serve on an advisory board (Roche), from attorneys for providing expert medical witness opinions, and is a member of the Board of Directors for the Society of Cardiovascular Patient Care.

\section{References}

1. http://www.abim.org/certification/. Accessed 17 Sept 2014.

2. http://www.jointcommission.org/accreditation/accreditation_main. aspx. Accessed 17 Sept 2014.

3. https://www.lipid.org/education/certification. Accessed $17 \mathrm{Sept}$ 2014.

4. http://www.nursecredentialing.org/Magnet. Accessed 17 Sept 2014.

5. http://www.abms.org/About_ABMS/ABMS_History/Extended History/Competency_Movement.aspx. Accessed 17 Sept 2014.

6. Holmboe ES, Wang Y, Meehan TP, Tate JP, Ho SY, Starkey KS, et al. Association between maintenance of certification examination scores and quality of care for Medicare beneficiaries. Arch Int Med 2008;163:1396-403.

7. Chen J, Rathore SS, Wang Y, Radford MJ, Krumholz HM. Physician board certification and the care and outcomes of elderly patients with acute myocardial infarction. J Gen Intern Med 2006;21:238-44.

8. Tamblyn R, Abrahamowicz M, Brailovsky C, Grand'Maison P, Lescop J, Norcini J, et al. Association between licensing examination scores and resource use and quality of care in primary care practice. J Am Med Assoc 1998;280:989-96.

9. Chatterjee P, Joynt KE. Do cardiology quality measures actually improve patient outcomes? J Am Heart Assoc 2014;3:e000404.

10. Menees DS, Peterson ED, Wang Y, Curtis JP, Messenger JC, Rumsfeld JS, et al. Door-to-balloon time and mortality among patients undergoing primary PCI. N Engl J Med 2013;369:901-9.

11. http://www.jointcommission.org/assets/1/6/F_242464_13_Organd AffInc_CFS.pdf. Accessed 17 Sept 2014.

12. http://www.abms.org/ABMS_2012_2013_Review/. Accessed 17 Sept 2014.

13. Centor RM, Fleming DA, Moyer DV. Maintenance of certification: Beauty is in the eyes of the beholder. Ann Int Med 2014;161:226-7.

14. http://www.cms.gov/Medicare/Provider-Enrollment-and-Certification/ MedicareProviderSupEnroll/AdvancedDiagnosticImagingAccredit ation.html. Accessed 17 Sept 2014.

15. Governmental Accountability Office. Medicare Imaging Accreditation: Establishing Minimum National Standards and an Oversight Framework Would Help Ensure Quality and Safety of Advanced Imaging Services. May 2013; GAO-13-246

16. http://www.cms.gov/Regulations-and-Guidance/Legislation/NationalPhysician-Payment-Transparency-Program/index.html. Accessed 17 Sept 2014.

17. http://www.cardiosource.org/ /media/Files/ACC/About/2013/05/ Principles\%20for\%20Relationships\%20with\%20Industry\%20130 520.ashx. Accessed 17 Sept 2014.

18. Jerome SD, Farrell MB, Godiwala T, Heller GV, Bezold LI, Choi JY, et al. Facility perception of nuclear cardiology accreditation: Results of an Intersocietal Accreditation Commission (IAC) survey. J Nucl Cardiol 2014. doi:10.1007/s12350-014-0011-5.

19. http://www.intersocietal.org/iac/about/companymission.htm. Accessed 17 Sept 2014.

20. http://www.jointcommission.org/pneumonia/. Accessed $17 \mathrm{Sept}$ 2014. 